\title{
SIMULAÇÃO OPERACIONAL DE UMA TORRE DE DESTILAÇÃO ATMOSFÉRICA VIA ASPEN PLUS E AVALIAÇÃO DE MODELOS DE ANALISADORES VIRTUAIS
}

\author{
F.C. Diehl* \\ diehleenq.ufrgs.br \\ L.P. Lusa ${ }^{\dagger}$ \\ leandro@trisolutions.com.br
}

\author{
A.R. Secchi* \\ argedenq.ufrgs.br \\ L.A.R. Muniz \\ larmuniz@ucs.br
}

\author{
L.G.S. Longhi ${ }^{\S}$ \\ longhiapetrobras.com.br
}
* Grupo de Integração, Modelagem, Simulação, Controle e Otimização de Processos (GIMSCOP) Departamento de Engenharia Química, Universidade Federal do Rio Grande do Sul (UFRGS)
R. Luis Englert, s/n. Campus Central. CEP: 90040-000 - Porto Alegre, RS - BRASIL

${ }^{\dagger}$ TriSolutions - Soluções em Engenharia Rua General Bento Martins, 24 cj 1101 - CEP: 90010.080 - Porto Alegre, RS - BRASIL

${ }^{\ddagger}$ Grupo de Modelagem, Simulação e Controle de Processos Departamento de Engenharia Química, Universidade de Caxias do Sul (UCS) Rua Francisco Getúlio Vargas, 1130. CEP 95020-972 - Caxias do Sul, RS - BRASIL

${ }^{\S}$ G4ALBERTO PASQUALINI - REFAP S/A

Av. Getúlio Vargas, 11001, CEP 92420-221 - Canoas - RS - BRASIL

\section{RESUMO}

A torre atmosférica é um dos equipamentos mais importantes de uma unidade de destilação de óleo cru em uma refinaria. A otimização da operação deste equipamento é uma meta constante neste tipo de indústria, pois ela possibilita retornos financeiros bastante atrativos. Para levar a operação da coluna de destilação atmosférica próximo ao seu ponto operacional ótimo é necessário medir algumas propriedades chaves, em tempo real, para a atuação do sistema de controle. No entanto algumas propriedades não são facilmente medidas em tempo real, ou ainda sua medição depende da compra de analisadores em linha que podem apresentar custos expressivos. Uma alternativa para a obtenção dessas propriedades é a uti-

Artigo submetido em 27/01/2008 (Id.: 00851)

Revisado em 01/11/2008, 10/12/2008, 24/12/2008

Aceito sob recomendação do Editor Associado Prof. Takashi Yoneyama lização de inferências (analisadores virtuais), que predizem a variável desejada através de modelos matemáticos utilizando variáveis secundárias como parâmetros de entrada. Duas inferências, concedidas pela REFAP S/A, foram avaliadas com a finalidade de se determinar aquela com maior poder preditivo da temperatura que destila $85 \%$ da corrente de hidrocarbonetos desejada (T85\%). A fonte de dados, para os testes, foi originada no estado estacionário pelo software Aspen Plus, após a validação de um modelo por dados operacionais médios recolhidos na própria refinaria. Dois modos operacionais foram propostos e análises de sensibilidade foram geradas para que seus resultados fossem utilizados como fonte de dados para os modelos inferenciais. As T85\% provenientes do simulador foram consideradas padrão para a comparação com os resultados obtidos pelas inferências. Os analisadores virtuais mostraram-se sensíveis ao modo de operação a que estão submetidos. Isto significa que os ajustes feitos nos 
parâmetros dos modelos devem ser revistos caso haja uma mudança operacional significativa no sistema de destilação. Para a operação em que os modelos foram desenvolvidos o desempenho das duas inferências foi semelhante, podendo concluir que no estado estacionário as predições de ambas são satisfatórias.

PALAVRAS-CHAVE: Inferências. Softsensors. Simulação. Torre atmosférica. Destilação.

\section{ABSTRACT}

The atmospheric tower is one of the most important equipments of an unit of distillation of raw oil in a refinery. The optimization of the operation of this equipment is a constant goal in this industry type, because it makes possible plenty financial returns attractive. To take the operation of the close column of atmospheric distillation to its optimal operational point it is necessary to measure some key properties, in real time, for the performance of the control system. However some properties are not measured easily in real time, or still its measurement depends on the purchase of on-line analyzers that they can present expressive costs. An alternative for the obtaining of those properties is the use of inferences (virtual analyzers), that predict the variable wanted through mathematical models using secondary variables as entrance parameters. Two inferences, granted by REFAP S/A, were appraised with the purpose of determining that with larger predictive power of the temperature that distils $85 \%$ of the current of wanted hydrocarbons (T85\%). The source of data, for the tests, it was originated in the stationary state by the software Aspen Plus, after the validation of a model for medium operational data collected in the own refinery. Two operational manners were proposed and sensibility analyses were generated so that their results were used as source of data for the inferential models. T85\% coming of the simulator were considered pattern for the comparison with the results obtained by the inferences. The virtual analyzers were shown sensitive to the operation way the one that is submitted. This means that the adjustments done in the parameters of the models should be reviewed in case there is a significant operational change in the distillation system. For the operation in that the models were developed the acting of the two inferences was similar, could conclude that in the stationary state the predictions of both are satisfactory.

KEYWORDS: Inferences. Softsensors. Simulation. Atmospheric tower. Distillation.

\section{INTRODUÇÃO}

A tradicional visão de sistemas automatizados é a da substituição da mão de obra por máquinas. Todavia a automação industrial vem passando por radicais mudanças. Tecnologias modernas de informação em tempo real sobre a administração e manufatura de processos vêm tornando-se populares à medida que proporcionam incrementos na otimização da eficiência de sistemas de controle (Bakhtadze, 2004).

A predição de propriedades de difícil aquisição por sistemas convencionais de análise pode ser realizada, de forma indireta, por analisadores virtuais, através da medida de variáveis correlacionadas à propriedade que se deseja estimar (Gonzalez, 1999).

Hoje, o desenvolvimento de analisadores virtuais é feito através da seleção de variáveis secundárias, técnicas de modelagem lineares ou não-lineares e técnicas computacionais (Conz, 2005). As variáveis secundárias são aquelas de fácil aquisição. Por exemplo, em uma coluna de destilação, as composições de produtos são normalmente variáveis a serem inferidas, enquanto que as variáveis secundárias são temperaturas, pressões e vazões. Entre os métodos de seleção das variáveis secundárias, destacam-se os baseados em análises combinatórias, análises de sensibilidade, buscas aleatórias e os métodos evolutivos, que consistem em adicionar ou remover variáveis buscando o aprimoramento do modelo em questão (Fortuna et al., 2007). Existem também métodos de seleção de variáveis baseados na heurística de engenheiros e técnicos do processo em questão (Conz, 2005).

Existe inúmeros métodos de análise de dados e teorias de controle que são utilizados para o projeto de analisadores virtuais. Esses métodos abrangem principalmente a modelagem tradicional e os algoritmos avançados, também conhecidos como inteligência computacional. A utilização de métodos de inteligência computacional tende a solidificar-se com o aumento da velocidade dos processadores eletrônicos (Bakhtadze, 2004).

Dentre os métodos de inteligência computacional existentes destacam-se as redes neuronais, a lógica fuzzy, os algoritmos genéticos, etc. A lógica fuzzy é uma extensão da lógica Booleana. A experiência mostra que os tempos e custos com projetos que utilizam lógica fuzzy são muito mais baixos do que os que utilizam ferramentas matemáticas. Porém a precisão dos resultados não é tão boa em comparação a aproximações probabilísticas (Bakhtadze, 2004). A maioria dos analisadores virtuais introduzidos no mercado por líderes mundiais, como a Siemens e a Honeywell, são softwares baseados em tecnologia de redes neuronais (neural network). Dentre as principais características dessa tecnologia está sua potencialidade de interpolação, antecipação e processamento paralelo. A grande dificuldade em relação à solidificação das redes neuronais, em processos dinâmicos, é no ajuste ("treinamento") da rede, já que é praticamente impossível predizer o seu comportamento sem começar a operação em tempo real 
(Bakhtadze, 2004).

No caso de colunas de destilação é comum a utilização de modelos baseados em métodos empíricos multivariáveis (Conz, 2005). Esses diferem dos modelos teóricos e semiempíricos por sua baixa complexidade. Atualmente a técnica PLS (Partial Least Squares) é a mais utilizada para inferir propriedades em colunas de destilação, já que busca maximizar a covariância entre dados de entrada e saída (Conz, 2005).

Hoje em dia, os analisadores virtuais fazem parte do cotidiano de torres de destilação em refinarias e petroquímicas, já que a otimização é uma meta constante nessas indústrias (Longhi et al., 2007; Miranda e Lusa, 2003; Conz et al., 2005). Tendo em vista que a qualidade de uma inferência é dada pela sua capacidade de predição de uma propriedade chave, torna-se imprescindível a comparação de diferentes inferências visando à determinação daquela de maior precisão.

No presente trabalho são avaliados dois modelos de inferências, concebidos pela REFAP S/A, para a predição de uma propriedade fundamental na caracterização dos produtos resultantes da destilação atmosférica de óleo cru: a curva de destilação. Mais precisamente a temperatura que destila $85 \%$ da corrente em questão (T85\%), sendo de suma relevância seu conhecimento, pois essa porcentagem é uma especificação do óleo diesel e limita a adição de frações pesadas no mesmo (Riazi, 2005). Em misturas multicomponentes as variáveis medidas podem indicar o nível de separação alcançada e alimentar os controladores, alcançando as especificações dos produtos (Kalid, 2006). Caso existam analisadores em linha, o seu sinal pode ser utilizado como variável medida. Porém nem sempre é viável a instalação de analisadores em linha, seja por motivos técnicos (não dispor de sistemas de condicionamento de amostras) ou por motivos econômicos (em geral os instrumentos apresentam elevados custos). Então se pode inferir a composição a partir de analisadores virtuais.

A metodologia adotada envolve o desenvolvimento de um modelo da coluna, através do software de simulação Aspen Plus (Aspentech, 2001a), para gerar os dados utilizados como entradas para os analisadores virtuais. Os valores padrão da propriedade, utilizados para as comparações, foram gerados por este simulador através de uma estimativa que equivale à curva de destilação descrita na norma D86 da American Society for Testing and Materials (ASTM, 2007) para misturas de petróleos. Essa norma, grosso modo, é uma destilação diferencial (em batelada) sob condições controladas de ensaio.

\section{UNIDADE DE DESTILAÇÃO}

A primeira etapa da separação do petróleo em diversas frações com diferentes propriedades é tradicionalmente feita através de destilação fracionada, chamada de destilação atmosférica. O processo tem esse nome por operar em pressões próximas à pressão barométrica. Segundo Watkins (1981) o equipamento de separação é projetado para gerar cinco correntes de destilado e uma de fundo, também chamada de resíduo atmosférico (RAT). A fração mais leve nem sempre é completamente condensável nas condições de temperatura e pressão do vaso de refluxo, o que resulta em uma corrente líquida e uma vapor na saída do condensador. Uma quantidade de vapor de água, chamada overflash ou vapor de retificação, é injetada na coluna com vistas a promover um refluxo adequado entre a zona de flash e a região de alimentação, parcialmente vaporizada, e diminuir a pressão parcial dos componentes facilitando o processo de separação. Em geral a alimentação é aquecida até a temperatura de operação pelo fato dessas colunas não possuírem refervedores. Neste processo é comum a remoção de calor através de refluxos laterais, chamados pumparounds (RCI e RCS; reciclo circulante inferior e superior, respectivamente) (Parkash, 2003).

Para controlar o ponto inicial de ebulição da curva ASTM D86, cada corrente lateral é mandada a uma coluna retificadora (stripper), que contém um refervedor parcial ou uma injeção de vapor de água (Perry et al., 1999). Isso quer dizer que os strippers ajustam o produto removido até o ponto inicial de ebulição desejado, o que garante a qualidade da corrente efluente. A fração que não se enquadra nessas especificações retorna à torre de destilação.

A Figura 2.1 esquematiza a torre de destilação atmosférica utilizada na refinaria REFAP S/A. Os números das correntes indicam o estágio em que se encontram na coluna, sendo que o condensador foi considerado como primeiro estágio. No total, a torre possui 45 pratos com válvulas Glitsh de 2 polegadas e na região de alimentação usam-se recheios Mellapack. Sua altura total é de aproximadamente 57 metros com diâmetros inferior e superior de 4,5 e 7,5 metros, respectivamente. $\mathrm{O}$ equipamento ainda apresenta strippers, de 4 estágios com injeção de vapor, nas correntes de diesel pesado, diesel leve, querosene e nafta pesada (Perry et al., 1999; Watkins, 1981; Matar e Hatch, 2000).

\section{SIMULAÇÃO OPERACIONAL}

A simulação computacional é uma ferramenta poderosa na resolução de problemas referentes à engenharia química. Ela permite predizer o comportamento de processos usando relações básicas, tais como balanços de massa, energia e equilíbrio termodinâmico, e específicas de cada equipamento (Aspentech, 2001a). Desde a década de 60 esta tecnologia vem 


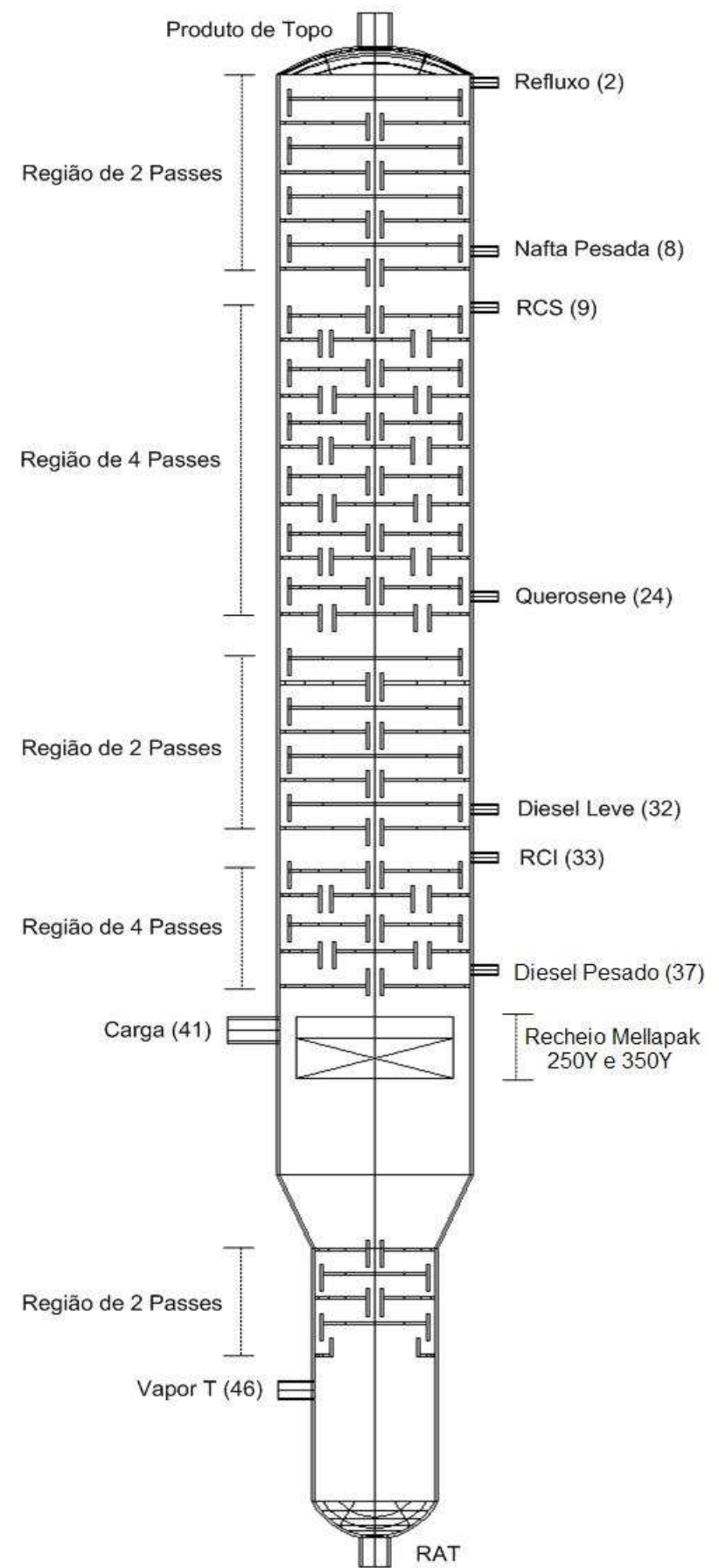

Figura 2.1 - Torre de destilação atmosférica da REFAP S/A (Petrobrás).

sendo utilizada e desenvolvida, todavia originalmente, devido a restrições computacionais, a simulação era utilizada somente com finalidades de projeto. Hoje, adicionalmente ao projeto, a simulação é aplicada ao treinamento de operadores, otimizações de processos, apoio a decisões, estudos de sensibilidade e, mais recentemente, no apoio ao controle

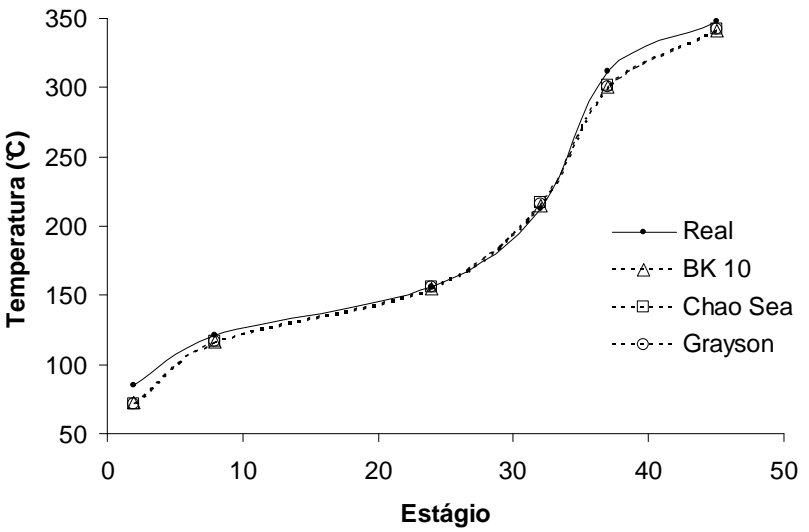

Figura 3.1 - Especificação: fração de vapor destilado (condensador) e vazão de RAT.

avançado de processos (Ondrey, 2005).

A simulação da torre de destilação atmosférica validada é uma importante ferramenta para os testes das inferências, pois permite predizer as propriedades dos produtos efluentes em diversas situações. Neste artigo, as simulações foram feitas no software Aspen Plus e seus resultados validados através de dados provenientes de planta real.

Um dos maiores problemas no que se refere à predição de comportamentos em processos de refinarias é a caracterização da carga. O petróleo, matéria-prima dessa classe industrial, apresenta uma série de variações na composição que dependem da região de onde é extraído, podendo variar tanto em densidade quanto na sua composição química. Quando da coleta dos dados para a modelagem, a REFAP S/A utilizava aproximadamente $80 \%$ de petróleo leve e $20 \%$ de petróleo pesado, com grau API de 42,6 e 20,8, respectivamente. A curva de destilação, desses dois petróleos, foi utilizada como entrada no simulador, para caracterizar a alimentação da unidade.

Além disso, a qualificação das inferências e a criação de um modelo representativo requerem uma série de dados operacionais. Esses dados foram extraídos do histórico da unidade, em uma situação em que o processo se encontrava em estabilidade operacional.

Como pode ser observado nas Figuras 3.1 a 3.4, as especificações mais adequadas para a representação do processo real envolvem a vazão de RAT e a temperatura do condensador ou fração de vaporizado do mesmo, para termodinâmicas apolares (Braun K10, Chao-Seader, Grayson-Streed). Com a utilização do modelo UNIFAC a simulação não convergiu em nenhum dos casos, e o modelo NRTL-RK convergiu apenas em uma das situações apresentando resultados insatisfatórios. Detalhes e descrições dos modelos termodinâmicos são descritos em Aspentech (2001b). 


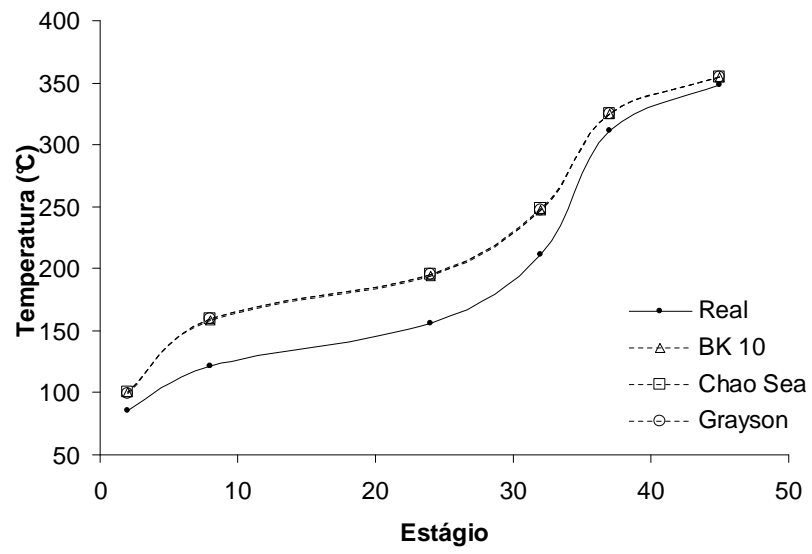

Figura 3.2 - Especificação: temperatura do condensador e vazão total de destilado.

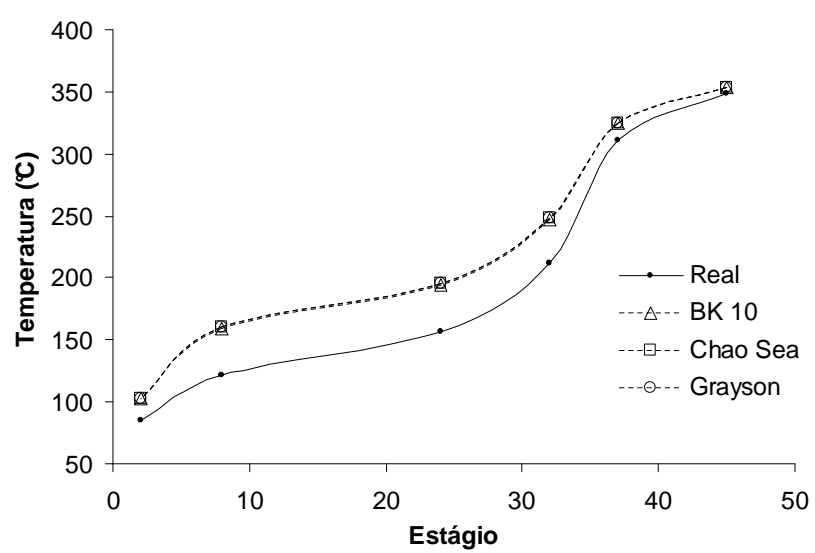

Figura 3.3 - Especificação: fração de vapor destilado (condensador) e vazão total de destilado.

A determinação da situação que melhor descreve o processo torna-se uma tarefa difícil já que visualmente há pouca diferença entre os resultados das Figuras 3.1 e 3.4 para as ter-

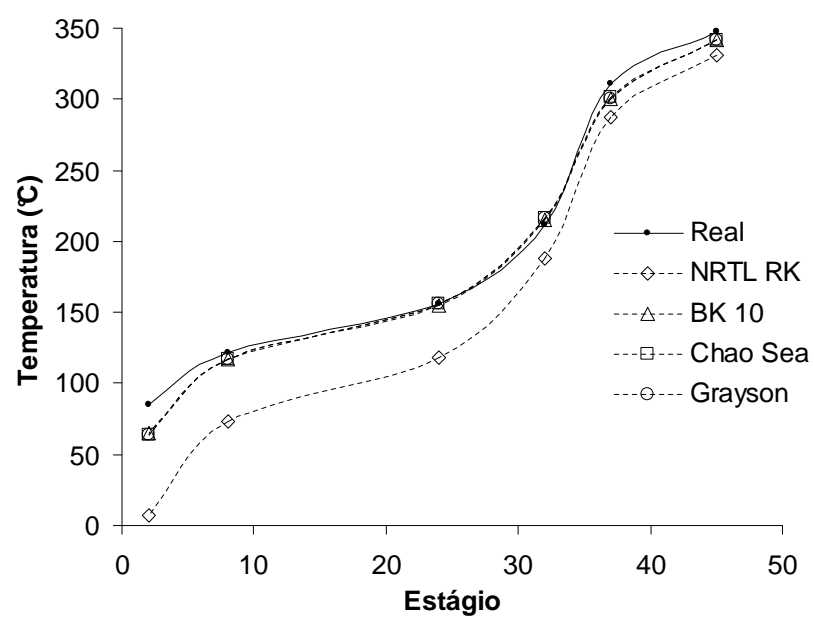

Figura 3.4 - Especificação: temperatura do condensador e vazão de RAT.

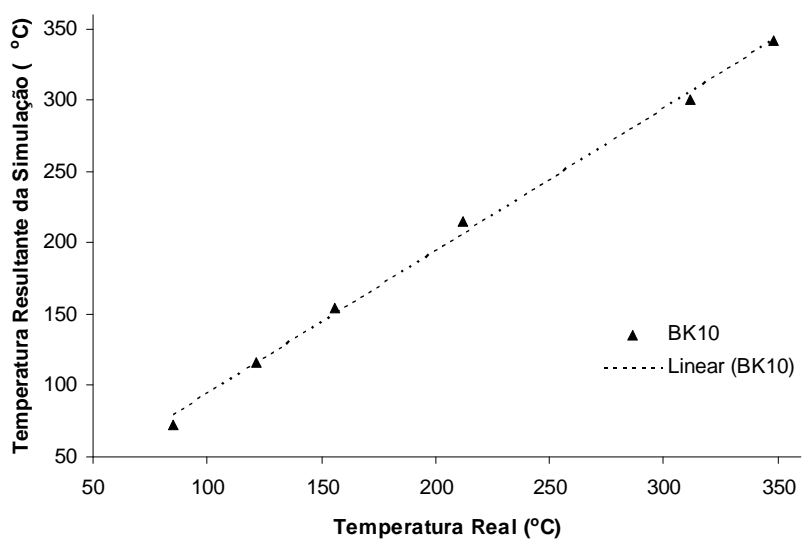

Figura 3.5 - Temperatura real versus simulada

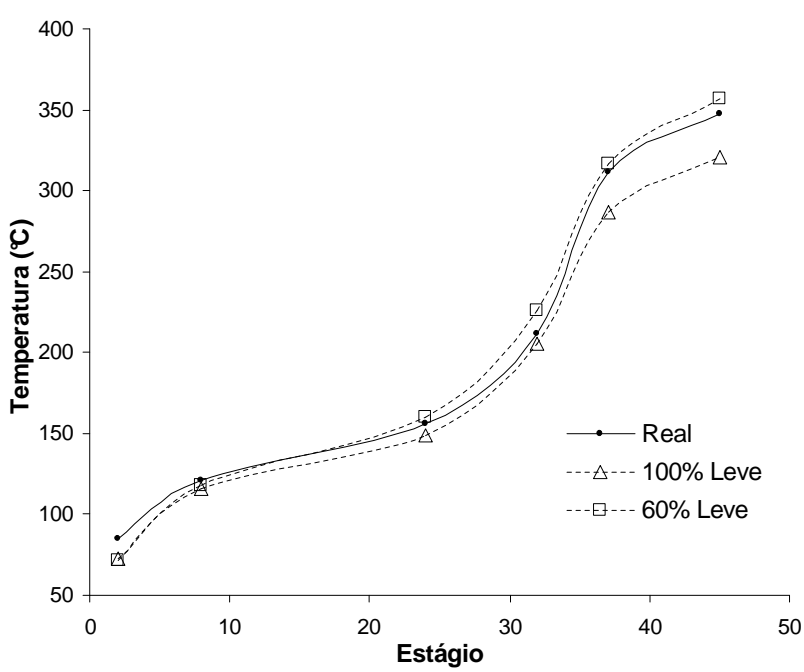

Figura 3.6 - Perfil de temperatura frente à variação da composição da carga.

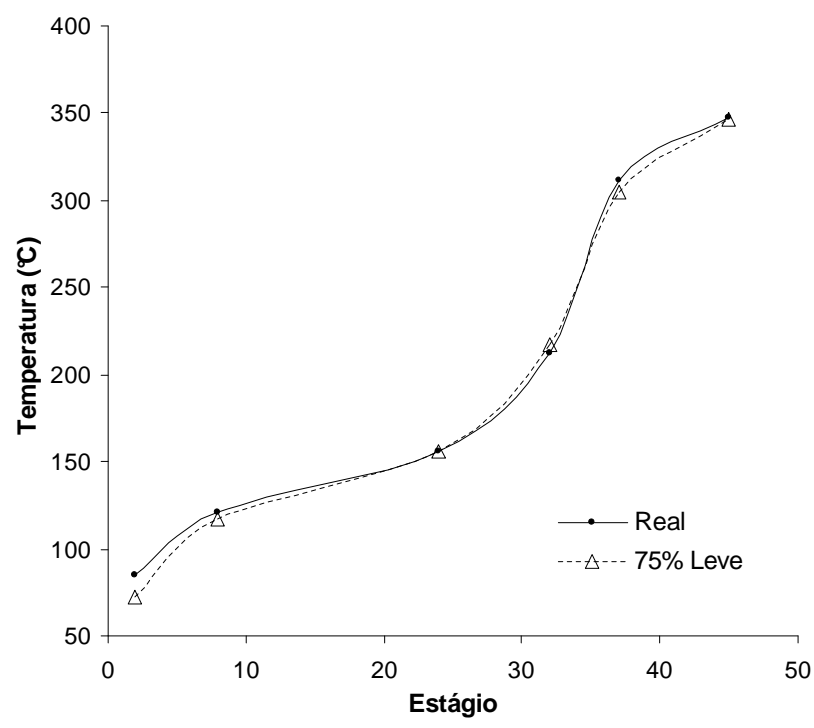

Figura 3.7 - Resultados para a simulação com $75 \%$ de petróleo leve e $25 \%$ de pesado. 
modinâmicas apolares. Sendo assim uma análise mais adequada se faz necessária e a Figura 3.5 mostra uma forma de comparação quantitativa dos resultados, onde Linear (BK10) ilustra o melhor ajuste linear para os pontos do gráfico. A Tabela 3.1 relaciona as inclinações dos ajustes lineares dos resultados apresentados nas Figuras 3.1 e 3.4 para os modelos BK10, Chao-Seader e Grayson-Streed. A simulação utilizando o modelo BK10 (que é próprio para aplicações com petróleo) com a temperatura do condensador e a vazão de RAT especificadas apresentou os melhores resultados.

Definida a termodinâmica e as especificações de operação, foi ajustada a composição da carga, já que não se conhece ao certo que mistura de petróleo foi utilizada no período analisado. Isto porque os tanques que armazenam petróleo possuem sistemas de agitação, por turbinas, que visam a homogeneização das frações leves e pesadas que são aspiradas para o processo. Sendo assim os tanques não podem trabalhar com níveis muito baixos e, portanto, novos petróleos são adicionados tornando a exatidão de definição da carga uma difícil tarefa. Outro fator que justifica o ajuste é que o monitoramento da vazão, na refinaria, é realizado por sensores de placa de orifício, fato este que reduz a credibilidade e confiabilidade de suas medidas. A relação entre o petróleo leve e pesado foi variada e analisada, e a Figura 3.6 mostra os resultados obtidos.

Tabela 3.1 - Análise quantitativa

\begin{tabular}{|c|c|c|c|}
\hline Figura & Termodinâmica & Inclinação & $\mathrm{R}^{2}$ \\
\hline & BK 10 & 1,0142 & 0,9946 \\
\hline 3.1 & Chao-Seader & 1,0171 & 0,9933 \\
\hline & Grayson-Streed & 1,0190 & 0,9935 \\
\hline & BK 10 & 1,0007 & 0,9968 \\
\hline 3.4 & Chao-Seader & 1,0010 & 0,9959 \\
\hline & Grayson-Streed & 1,0025 & 0,9961 \\
\hline
\end{tabular}

Através do somatório do erro quadrado foi possível determinar qual composição de petróleo leve e pesado se adapta melhor as condições de operação real. Este valor ficou em torno de $75 \%$ de petróleo leve e $25 \%$ de pesado e o resultado para essa composição pode ser visualizado na Figura 3.7. O modelo que gerou os resultados da Figura 3.7 será utilizado para a análise de sensibilidade apresentada a seguir.

\section{ANÁLISE DE SENSIBILIDADE}

A análise de sensibilidade fornece informações sobre as respostas do processo frente a modificações em variáveis manipuladas (Secchi et al., 2006). Duas linhas de análise de sensibilidade são apresentadas a seguir, buscando representar diferentes formas de operação. A primeira delas visa controlar a quantidade produzida enquanto que a segunda visa controlar o perfil de temperatura da coluna. A T85\% foi analisada para diferentes misturas das correntes de produtos também chamadas de alinhamentos, onde as misturas dos produtos laterais nafta pesada (NP), querosene (Q), diesel pesado (DP) e diesel leve (DL) são:

$$
\begin{gathered}
\text { Alinhamento } A=N P+Q+D L+D P \\
\text { Alinhamento } B=N P+D L+D P \\
\text { Alinhamento } C=Q+D L+D P \\
\text { Alinhamento } D=D L+D P
\end{gathered}
$$

A abrangência das análises de sensibilidade foi determinada pelas variáveis manipuladas na carga, ou seja, as mesmas foram variadas ao máximo, até a simulação apresentar problemas de convergência. Os resultados gerados nestas análises serão os dados de entrada da avaliação dos analisadores virtuais. Todas as análises de sensibilidade foram simuladas no software Aspen Plus, e seus resultados gráficos são mostrados nas Figuras 4.1 a 4.6, onde as curvas T85_ $n$ representam os quatro alinhamentos A, B, C e D.

\subsection{Primeira linha de operação (PLO)}

Esta análise de sensibilidade visa observar o comportamento do sistema de destilação atmosférica com as vazões de produtos laterais fixas, independentemente dos distúrbios provocados. Isto significa a busca de um regime de operação com controle das quantidades produzidas.

Em operação, a coluna possui controle da temperatura do topo, que foi adicionada à simulação manipulando-se a temperatura do condensador. A vazão do fundo é variável, já que controla o nível do fundo da torre, e apresenta oscilações dependentes dos distúrbios sofridos pelo processo. Assim sendo, manter a vazão de RAT constante, independente das variações na operação, não é a melhor especificação. Com vista a contornar este problema, a vazão do fundo ajustase para manter a temperatura do último estágio em $347,9^{\circ} \mathrm{C}$, como no processo real, já que não é possível trabalhar com o nível do fundo. A tolerância dos controladores é de $\pm 1^{\circ} \mathrm{C}$.

As Figuras 4.1, 4.2 e 4.3 mostram o comportamento da T85\% para uma variação da temperatura da carga $\left(368-380^{\circ} \mathrm{C}\right)$, da vazão de alimentação (+/-3\% do valor nominal) e da composição de entrada ( 23 - $27 \%$ de petróleo pesado), respectivamente.

Os gráficos apresentados permitem verificar a sensibilidade da $\mathrm{T} 85 \%$, para todos os alinhamentos, em relação às variações de estado da carga. Todos os dados operacionais rele- 


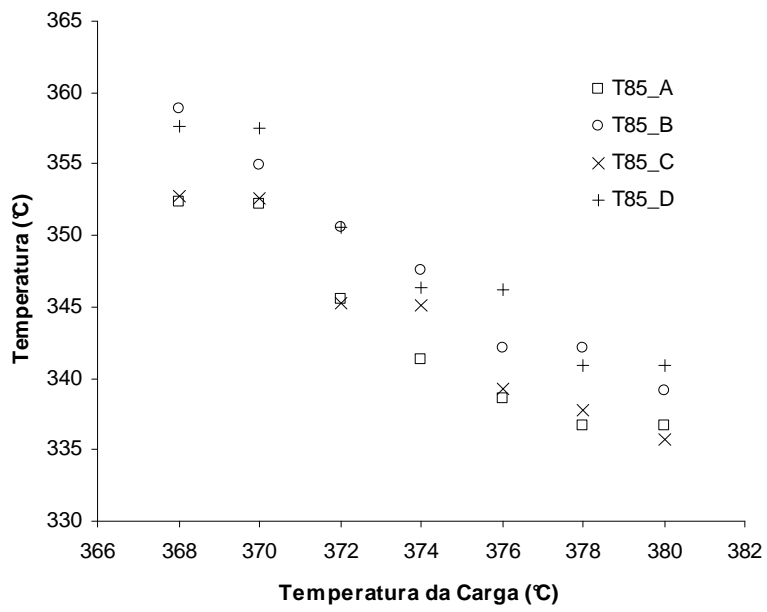

Figura 4.1 - Comportamento da T85\% frente a variações na temperatura da carga.

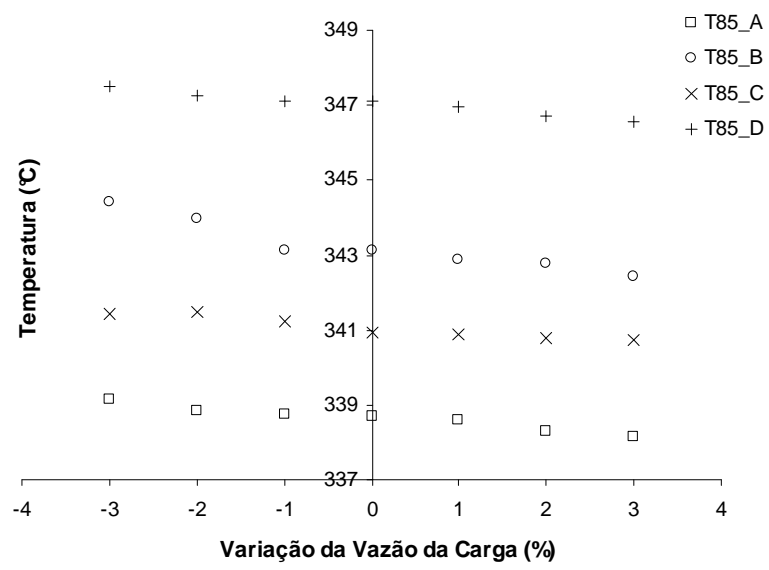

Figura 4.2 - Comportamento da T85\% frente a variações na vazão da carga.

vantes, às entradas das inferências, foram armazenados para posterior avaliação das mesmas.

\subsection{Segunda linha de operação (SLO)}

Esta análise de sensibilidade visa observar o comportamento do sistema de destilação atmosférica mantendo-se o perfil de temperatura interno fixo independentemente dos distúrbios provocados.

Primeiramente foi especificado o perfil de temperatura nos pontos de retiradas de produtos e no topo da coluna. Entretanto, as análises de sensibilidade não convergiam para amplitudes apropriadas nem mesmo com tolerância de $2^{\circ} \mathrm{C}$. Devido à rigidez das condições especificadas, a confiabilidade dos resultados gerados era questionável e, portanto, foi necessário alterar alguns pontos das variáveis em questão.

Ao invés de controlar todos os pontos de remoção de produ-

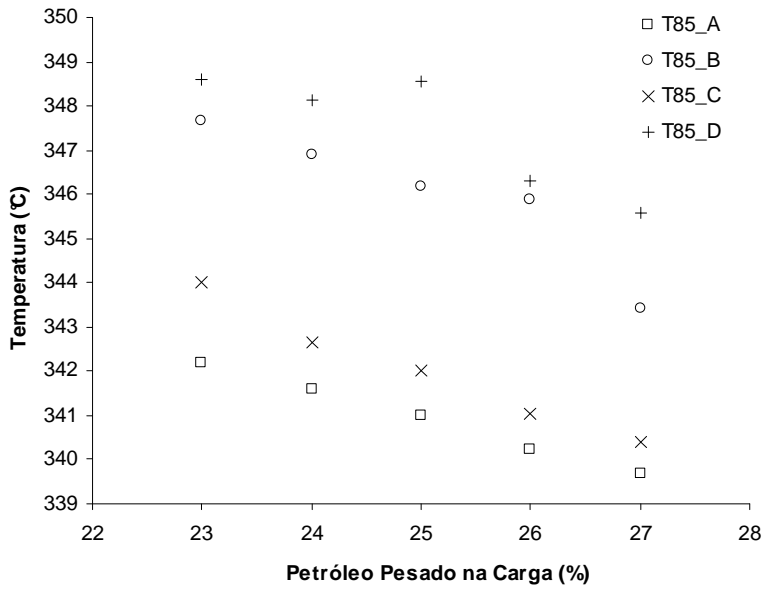

Figura 4.3 - Comportamento da T85\% frente a variações na composição da carga.

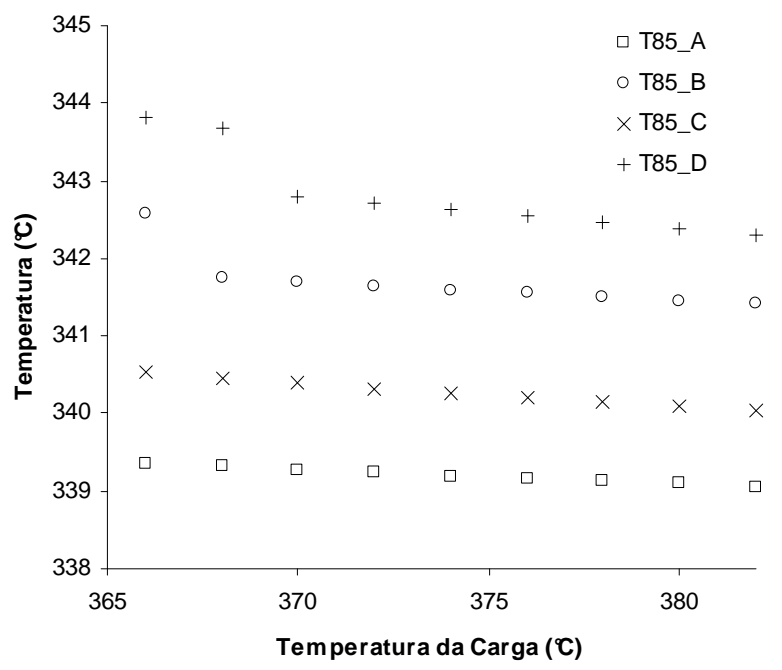

Figura 4.4 - Comportamento da T85\% frente a variações na temperatura da carga.

tos da coluna foram especificadas as temperaturas do topo e da corrente de diesel leve, enquanto que a vazão ficou fixada para as demais retiradas. A tolerância das variáveis manipuladas ficou em $0,1^{\circ} \mathrm{C}$. O diesel leve foi escolhido por ser um ponto intermediário entre as correntes de maior importância para os modelos de inferência. Os resultados do comportamento da T85\% estão apresentados nas Figuras 4.4, 4.5 e 4.6.

\section{INFERÊNCIAS}

Para que os controladores operem de forma eficiente são necessárias leituras em tempo real das propriedades de interesse. Isso torna factível ao sistema de controle a tomada de ações de caráter servo e regulatório. Entretanto, em refinarias, algumas propriedades não são facilmente quantificadas em tempo real, sendo necessárias análises laboratoriais, ou ainda sua medição depende da compra de analisadores em li- 


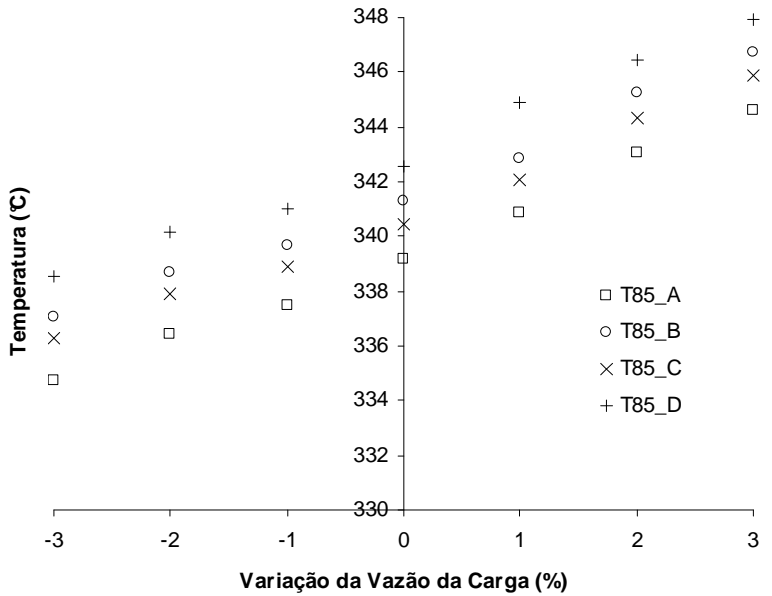

Figura 4.5 - Comportamento da T85\% frente a variações na vazão da carga.

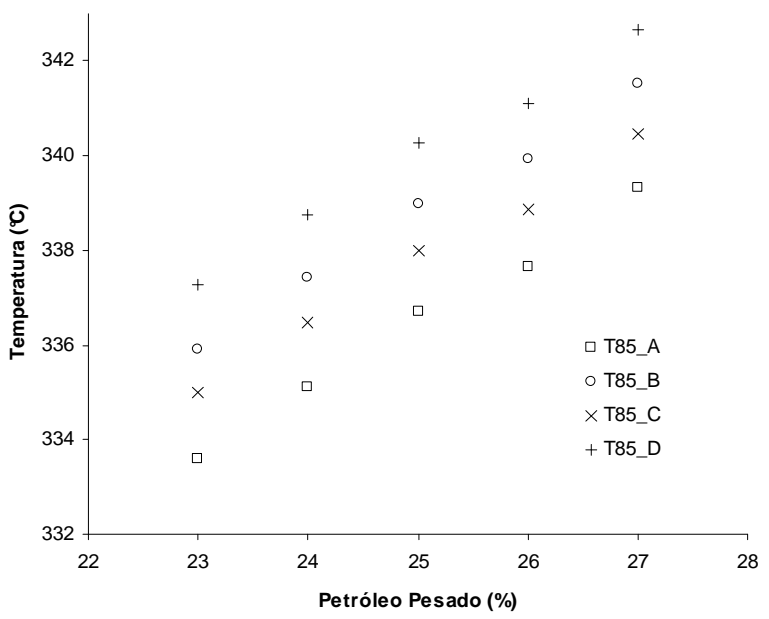

Figura 4.6 - Comportamento da T85\% frente a variações na composição da carga.

nha que podem ser excessivamente caros. A utilização direta de resultados de laboratórios é viável, todavia a freqüência de atualizações das propriedades é muito baixa, chegando, no máximo, a 6 vezes ao dia na REFAP S/A.

Como alternativa, surgem as inferências ou analisadores virtuais, que são módulos de cálculo que podem predizer propriedades chaves do produto através da medição de outras variáveis do processo de fácil obtenção. A inferência é basicamente constituída de algoritmos e modelos matemáticos e sua qualidade é medida pela precisão de suas estimativas (Miranda e Lusa, 2003).

A descrição das duas inferências avaliadas é apresentada a seguir, onde as unidades de temperatura e vazão são, respectivamente, ${ }^{\circ} \mathrm{C}$ e $\mathrm{m}^{3} / \mathrm{dia}$.

\subsection{Inferência semi-empírica simplificada}

Esta técnica é baseada em um modelo semi-empírico que se propõe a predizer a curva de destilação das correntes efluentes a partir das temperaturas das bandejas de retirada de produto da torre. Segundo Miranda e Lusa (2003), são modelos estacionários que necessitam periodicamente de fatores de correção baseados em resultados de laboratórios. Os autores afirmam que a implementação da análise virtual é simples e apresenta custos relativamente baixos, desde que exista um sistema de instrumentação e aquisição de dados já implantados. A manutenção da mesma também é simples, todavia a precisão dos seus resultados não é tão boa, e tampouco capaz de ajustar a sua predição para diferentes tipos de petróleo e/ou variações significativas nos refluxos internos da coluna. Os autores citam a desvantagem da correção de parâmetros através de resultados de laboratório, já que erros nas análises podem deteriorar a inferência e a variância da análise em laboratório é repassada automaticamente para a inferência.

A inferência semi-empírica simplificada é baseada em um modelo semi-empírico que visa predizer a curva de destilação dos produtos da destilação atmosférica a partir das temperaturas dos pratos de retirada e suas vazões de saída. A metodologia de cálculo pode ser encontrada em Miranda e Lusa (2003). Com vistas a proteger as vantagens competitivas da REFAP S/A, alguns parâmetros de ajuste estão substituídos por incógnitas na descrição a seguir.

Primeiramente, calcula-se a temperatura que destila $30 \%$ da corrente desejada.

$$
T_{30_{i}}=\alpha_{i} \cdot T_{i}+\text { Bias }_{i}
$$

$T_{30 i}$ Temperatura que destila $30 \%$ da corrente $\mathrm{i}$.

$\alpha_{i}$ Parâmetro ajustado com dados de laboratório.

$T_{i}$ Temperatura da bandeja de retirada de $\mathrm{i}$.

Bias $_{i}$ Parâmetro ajustado com dados de laboratório.

A temperatura que destila $85 \%$ da corrente é estimada pela Equação 2.

$$
T_{85 i}=\frac{0,55 F_{i}\left(T_{i-1}-T_{i}\right)}{0,7 F_{i}+0,3 F_{i-1}}+T_{30 i}
$$

$T_{85 i}$ Temperatura que destila $85 \%$ da corrente $\mathrm{i}$.

$T_{i-1}$ Temperatura da bandeja de retirada da corrente abaixo da corrente i.

$F_{i}$ Vazão da corrente i. 
$F_{i-1}$ Vazão da corrente abaixo da corrente i.

A inferência prediz ainda a T85\% de misturas das correntes efluentes da torre. Para isso é necessária a utilização das seguintes regras de mistura:

$$
\begin{gathered}
I_{85 i}=\left[\frac{32+1,8 T_{85 i}}{546,1}\right]^{7,8} \\
I_{85 m}=\frac{\sum I_{85 i} F_{i}}{\sum F_{i}} \\
T_{85 s b m}=\frac{546,1 \sqrt[7.8]{I_{85 m}}-32}{1,8}
\end{gathered}
$$

$I_{85 i}$ Índice da corrente $\mathrm{i}$.

$I_{85 m}$ Índice da mistura $\mathrm{m}$.

$T_{85 s b m}$ Temperatura que destila $85 \%$ da mistura m (sem bias).

A T85\% utilizada como parâmetro de especificação dos produtos foi corrigida por um fator chamado de Bias, que é a T85\% resultante de análises laboratoriais. No caso do presente trabalho, a T85\% do laboratório foi substituída pela T85\% resultante da simulação. O Bias foi calculado da seguinte maneira:

$$
\text { Bias }=T_{85 S}-T_{85 P}
$$

Bias Parâmetro de correção para o cálculo da T85\% da mistura.

$T_{85 S} \mathrm{~T} 85 \%$ resultante da simulação.

$T_{85 P}$ T85\% padrão para cada linha de operação resultante do modelo inferencial.

A T85\% padrão é aquela considerada real, ou seja, o valor base para a comparação com os valores preditos pelas inferências. As T85\% da simulação e a padrão foram calculadas para as duas linhas de operação mencionadas na análise de sensibilidade. Para cada uma das configurações operacionais foi determinado a $T_{85 S}$ pelo software Aspen Plus. A $T_{85 P}$ foi calculada pela inferência semi-empírica simplificada sem bias com dados de temperatura e vazão provenientes da simulação, uma para cada linha de operação.
A temperatura que destila $85 \%$ da mistura que se deseja analisar é calculada, então, pela Equação 7, onde Bias $_{m}$ é o Bias para a mistura $m$.

$$
T_{85 m}=T_{85 s b m}+\text { Bias }_{m}
$$

\subsection{Inferência de polinômios ajustados}

Outra maneira de predizer propriedades, muito usual, é a que utiliza medições do processo que apresentem sensibilidade à variação da propriedade que se quer inferir com entradas em um polinômio. Miranda e Lusa (2003), relatam que o desenvolvimento desse tipo de inferência envolve basicamente duas etapas; a primeira implica na seleção das medições mais indicadas e a segunda etapa consiste no desenvolvimento da inferência por ajuste de parâmetros de um polinômio, de uma rede neuronal ou qualquer outro método semelhante. Segundo os autores esta inferência requer um maior investimento em engenharia na seleção das variáveis relevantes e no desenvolvimento do polinômio. Sua implementação é tão simples quanto a semi-empírica simplificada, todavia sua manutenção merece uma atenção especial, necessitando de ajustes periódicos nos parâmetros. Esta técnica de inferência apresenta resultados mais precisos que a outra técnica, porém com baixa capacidade de ajustar-se a mudanças de composição da carga e necessita das mesmas correções laboratoriais que a inferência semi-empírica simplificada.

Os modelos utilizados nos testes foram concebidos pela REFAP S/A e com vistas a proteger as vantagens competitivas da empresa os parâmetros ajustados não serão apresentados. Para o cálculo da T85\% de cada retirada, foi utilizada a seguinte equação genérica:

$$
T_{n, i}=\sum_{j=1}^{j=6}\left(\alpha_{n, i, j} \cdot T_{j-1}^{\beta_{n, i, j}} \cdot\left(\frac{V_{i}}{V_{c \arg a}}\right)^{\gamma_{n, i, j}} \cdot P_{\text {topo }}^{\varphi_{n, i, j}}\right)
$$

Na Equação 8, os índices $i, j$ e $n$ representam, respectivamente, as correntes intermediárias (NP, Q, DL e DP), as temperaturas das panelas de retirada (topo, NP, Q, DL, DP e zona de $f$ lash) e as temperatura de destilação (T85\%), enquanto que $\alpha_{n, i, j}, \beta_{n, i, j}, \gamma_{n, i, j}$ e $\phi_{n, i, j}$ são constantes.

As regras de mistura para esta inferência variam de acordo com o alinhamento, ao contrário da inferência semi-empírica simplificada, que utiliza as mesmas regras de mistura para todos os alinhamento. Isto torna os modelos polinomiais mais flexíveis que os empíricos simplificados. As equações 9, 10, 11 e 12 são as inferências correspondentes aos alinhamentos $\mathrm{A}, \mathrm{B}, \mathrm{C}$ e D, respectivamente. 


$$
\begin{aligned}
& T_{\text {DlinA }}^{T 85}=x_{38}\left[F_{N P}^{x_{39}}\left(T_{N P}^{T 85}\right)^{x_{40}}\right]+ \\
& +x_{41}\left[F_{Q N}^{x_{42}}\left(T_{Q N}^{T 85}\right)^{x_{43}}\right]+x_{44}\left[F_{D L}^{x_{45}}\left(T_{D L}^{T 85}\right)^{x_{46}}\right]+ \\
& +x_{47}\left[F_{D P}^{x_{48}}\left(T_{D P}^{T 85}\right)^{x_{49}}\right]+x_{50}
\end{aligned}
$$$$
T_{D \operatorname{DinB}}^{T 85}=x_{51}\left[F_{N P}^{x_{52}}\left(T_{N P}^{T 85}\right)^{x_{53}}\right]+
$$$$
+x_{54}\left[F_{D L}^{x_{55}}\left(T_{D L}^{T 85}\right)^{x_{56}}\right]+
$$$$
+x_{57}\left[F_{D P}^{x_{58}}\left(T_{D P}^{T 85}\right)^{x_{59}}\right]+x_{60}
$$

$$
\begin{aligned}
T_{D \operatorname{lin} C}^{T 85}= & x_{61}\left[F_{Q N}^{x_{62}}\left(T_{Q N}^{T 85}\right)^{x_{63}}\right]+ \\
& +x_{64}\left[F_{D L}^{x_{65}}\left(T_{D L}^{T 85}\right)^{x_{66}}\right]+ \\
& +x_{67}\left[F_{D P}^{x_{68}}\left(T_{D P}^{T 85}\right)^{x_{69}}\right]+x_{70}
\end{aligned}
$$

$$
\begin{aligned}
T_{\text {DlinD }}^{T 85}= & x_{71}\left[F_{D L}^{x_{72}}\left(T_{D L}^{T 85}\right)^{x_{73}}\right]+ \\
& +x_{74}\left[F_{D P}^{x_{75}}\left(T_{D P}^{T 85}\right)^{x_{76}}\right]+x_{77}
\end{aligned}
$$

$T_{\text {DlinA }}^{T 85}$ Temperatura que destila $85 \%$ do alinhamento A sem correção de Bias.

$T_{\text {DlinB }}^{T 85}$ Temperatura que destila $85 \%$ do alinhamento B sem correção de Bias.

$T_{\text {DlinC }}^{T 85}$ Temperatura que destila $85 \%$ do alinhamento $\mathrm{C}$ sem correção de Bias.

$T_{\text {DlinD }}^{T 85}$ Temperatura que destila $85 \%$ do alinhamento D sem correção de Bias.

$T_{N P}^{T 85}$ Temperatura que destila $85 \%$ da corrente de nafta pesada.

$T_{Q N}^{T 85}$ Temperatura que destila $85 \%$ da corrente de querosene.

$T_{D L}^{T 85}$ Temperatura que destila $85 \%$ da corrente de diesel leve.

$T_{D P}^{T 85}$ Temperatura que destila $85 \%$ da corrente de diesel pesado.
$F_{N P}$ Vazão da corrente de nafta pesada.

$F_{Q N}$ Vazão da corrente de querosene.

$F_{D L}$ Vazão da corrente de diesel leve.

$F_{D P}$ Vazão da corrente de diesel pesado.

(9) Como na inferência semi-empírica simplificada, a de polinômios ajustados também utiliza um Bias atualizado periodicamente para a correção do modelo. O Bias é baseado na T85\% resultante de análises laboratoriais. No entanto, a T85\% do laboratório foi substituída pela T85\% gerada na simulação, da mesma maneira que na inferência semi-empírica simplificada. O Bias foi determinado pela Equação 6.

As T85\% da simulação e a padrão foram calculadas para as duas linhas de operação mencionadas anteriormente (PLO e SLO). Para cada uma das configurações operacionais foi determinada a $T_{85 S}$ pelo software Aspen Plus. A $T_{85 P}$ foi calculada pela inferência polinomial sem bias com dados de temperatura, pressão e vazão provenientes da simulação, uma para cada linha de operação.

A Equação 13 mostra o cálculo da T85\% para a mistura de correntes, onde " $Y$ " indica o alinhamento desejado.

$$
T_{Y}^{T 85}=T_{D \operatorname{lin} Y}^{T 85}+\text { Bias }_{Y}
$$

\section{RESULTADOS}

A partir dos dados obtidos na análise de sensibilidade pôdese testar a acurácia das inferências semi-empírica simplificada e de polinômios ajustados. Os testes foram divididos em duas configurações operacionais: a primeira linha de operação (PLO) e a segunda linha de operação (SLO). A Tabela 6.1 relaciona o tipo de operação com as fontes de dados da análise de sensibilidade realizada.

\subsection{PLO1}

A PLO1 é a primeira linha de operação para o caso 1, que nada mais é do que a análise de sensibilidade para a configuração operacional que visa manter constantes as vazões de saída dos strippers quando varia-se a temperatura da alimentação de petróleo no sistema de destilação.

A Figura 6.1 ilustra o comportamento da T85\% da simulação e dos modelos em relação à temperatura da alimentação de petróleo, para todos os alinhamentos. Um ajuste linear, nos dados de simulação, foi adicionado ao gráfico para reforçar a tendência do resultado. Este mesmo tratamento foi aplicado aos gráficos das Figuras 6.3, 6.6, 6.8, 6.9 e 6.12. A Figura 6.2 

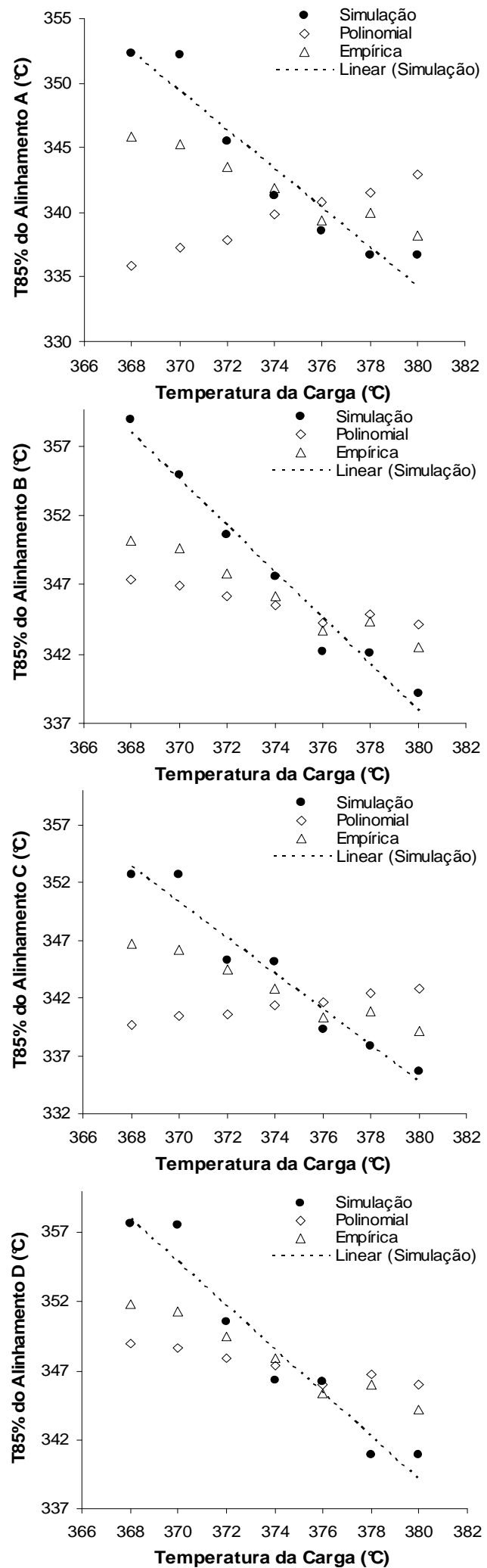

Figura 6.1 - PLO1: T85\% da simulação e dos modelos em relação aos distúrbios.
Tabela 6.1 - Fontes de dados para cada linha de operação

\begin{tabular}{|c|c|c|}
\hline Caso & PLO & SLO \\
\hline & $\begin{array}{c}\text { Simular a ação de } \\
\text { controle das vazões de } \\
\text { produtos laterais da } \\
\text { coluna de destilação }\end{array}$ & $\begin{array}{c}\text { Simular a ação de } \\
\text { controle do perfil } \\
\text { interno de } \\
\text { temperatura da coluna } \\
\text { de destilação }\end{array}$ \\
\hline \multicolumn{2}{|c|}{} \\
\hline 1 & $\begin{array}{c}\text { Análise de sensibilidade da variação da } \\
\text { temperatura da carga }\end{array}$ \\
\hline 3 & $\begin{array}{c}\text { Análise de sensibilidade da variação da vazão da } \\
\text { carga }\end{array}$ \\
\hline
\end{tabular}

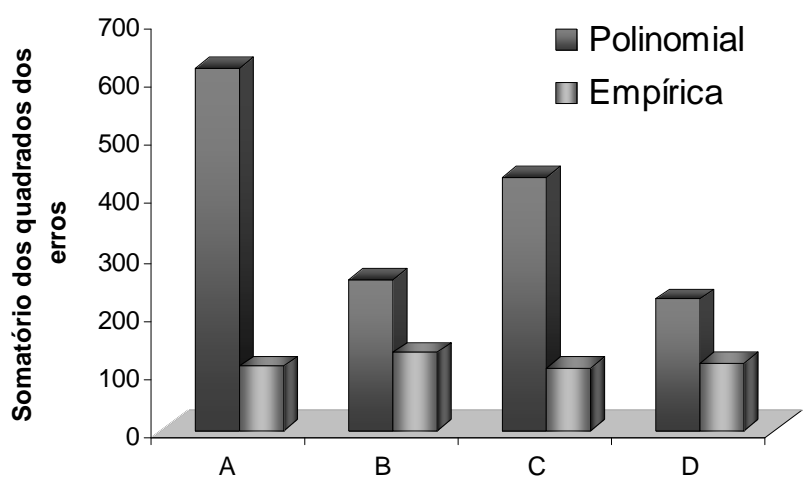

Figura 6.2 - PLO1: Comparação de desempenho dos analisadores virtuais.

apresenta o gráfico que relaciona o somatório dos erros quadrados da predição de cada modelo com o seu alinhamento.

Observa-se que a inferência polinomial teve um desempenho muito abaixo da semi-empírica. Se observados os valores preditos pelos modelos, para as temperaturas de $368^{\circ} \mathrm{C}$ e $370^{\circ} \mathrm{C}$ da carga, percebe-se que o modelo polinomial não conseguiu obter valores satisfatórios chegando a diferenças de mais de $15^{\circ} \mathrm{C}$ entre a sua predição da T85\% e a da simulação. Segundo a Figura 6.1, percebe-se que a inferência polinomial não consegue ajustar-se às tendências do processo. Nos alinhamentos A e C este modelo tem um comportamento inverso ao esperado.

Nas rotinas de cálculo, a inferência de polinômios ajustados não leva em conta as variações de vazão da corrente de resíduo atmosférico e a PLO manipula esta corrente para manter a temperatura do estágio 45 constante. Este fato faz com que a configuração operacional escolhida acabe prejudicando o modelo polinomial. Sendo assim o desempenho do modelo empírico simplificado é mais satisfatório nessas condições. 


\subsection{PLO2}

A PLO2 é a primeira linha de operação para o caso 2, ou seja, a análise de sensibilidade para a configuração operacional que visa manter constantes as vazões de saída dos strippers quando varia-se a vazão da carga alimentada.

A Figura 6.3 ilustra o comportamento da T85\% da simulação e dos modelos em relação à temperatura da alimentação de petróleo na torre, para os alinhamentos A, B, C e D. A Figura 6.4 apresenta o gráfico que relaciona o somatório dos erros quadrados da predição de cada modelo com o seu alinhamento.

A Figura 6.3 revela que o comportamento das inferências não é constante e, de um modo geral, o modelo empírico simplificado é melhor do que o de polinômios ajustados. Os alinhamentos A e C mostraram os maiores erros para a inferência polinomial, possivelmente as inferências que utilizam menos correntes na mistura têm maiores probabilidades de resultarem em boas predições, já que diminuem o número de variáveis envolvidas nas rotinas de cálculo.

A inferência semi-empírica simplificada acompanha o comportamento do processo com variações significativas, mas com erros menores, numa visão geral, do que o modelo polinomial. O comportamento do erro, na inferência polinomial, foi o mesmo do PLO1, onde os alinhamentos A e C mostraram-se menos confiáveis. Para essas misturas o valor predito pelo modelo tem uma sensibilidade muito acentuada em relação às propriedades geradas na simulação.

\subsection{PLO3}

A PLO3 é a primeira linha de operação para o caso 3, ou seja, a análise de sensibilidade para a configuração operacional que visa manter constantes as vazões de saída dos strippers quando varia-se a quantidade de petróleo leve e pesado da carga.

A Figura 6.5 apresenta o gráfico que relaciona o somatório dos erros quadrados da predição de cada modelo com o seu alinhamento. Já a Figura 6.6 ilustra o comportamento da T85\% da simulação e dos modelos em relação à temperatura da alimentação de petróleo na torre, para os alinhamentos A, $\mathrm{B}, \mathrm{C}$ e D.

Os resultados obtidos indicam que a inferência semiempírica simplificada tem maior capacidade de predizer a propriedade em questão para o caso analisado. Em todas as análises deste tópico sua eficiência foi superior à inferência polinomial.

Em relação à estabilidade da qualidade dos resultados percebe-se que o modelo empírico simplificado é mais ho-
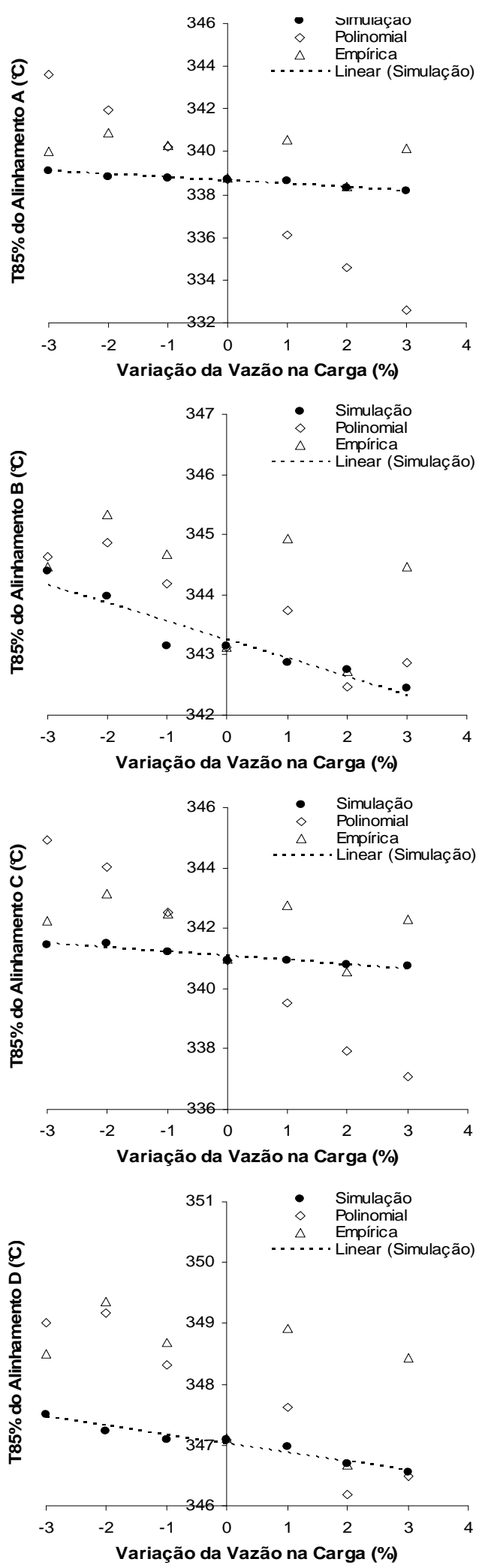

Figura 6.3 - PLO2: T85\% da simulação e dos modelos em relação aos distúrbios. 


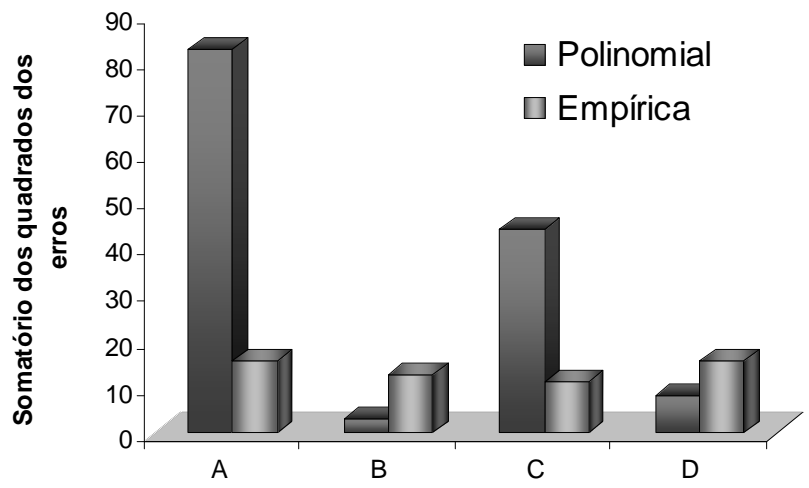

Figura 6.4 - PLO2: Comparação de desempenho dos analisadores virtuais

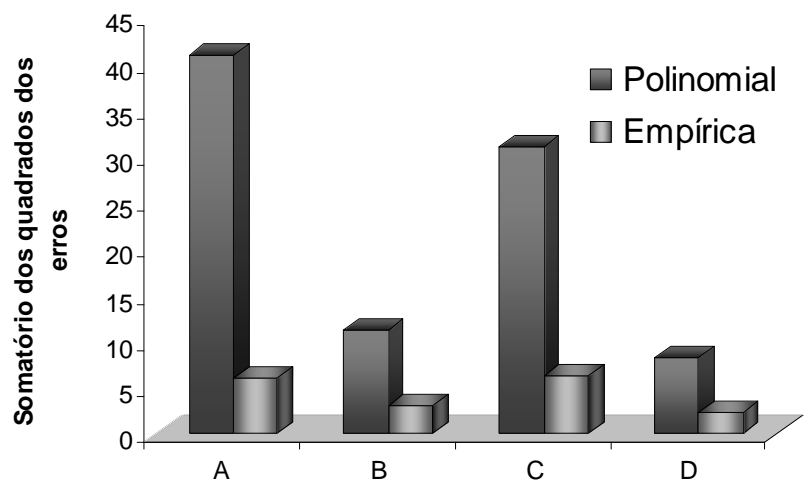

Figura 6.5 - PLO3: Comparação de desempenho dos analisadores virtuais.

mogêneo que o modelo de polinômios ajustados.

\subsection{SLO1}

A SLO1 é a segunda linha de operação para o caso 1, ou seja, a análise de sensibilidade para a configuração operacional que visa manter constante o perfil interno de temperatura da torre de destilação quando varia-se a temperatura da alimentação.

A Figura 6.7 apresenta o gráfico que relaciona o somatório dos erros quadrados da predição de cada modelo com o seu alinhamento. A Figura 6.8 ilustra o comportamento da T85\% da simulação e dos modelos em relação à temperatura da alimentação de petróleo na torre, para os alinhamentos A, B, C e D.

Como pode ser observado, ambas as inferências foram incapazes de predizer o comportamento do processo. Os valores resultantes da simulação, para esse caso, apresentaram variações significativas somente para as temperaturas da zona de flash e da corrente de RAT. Como a inferência polinomial leva em conta a temperatura da zona de flash e a semiempírica da corrente de RAT, provavelmente estas variações
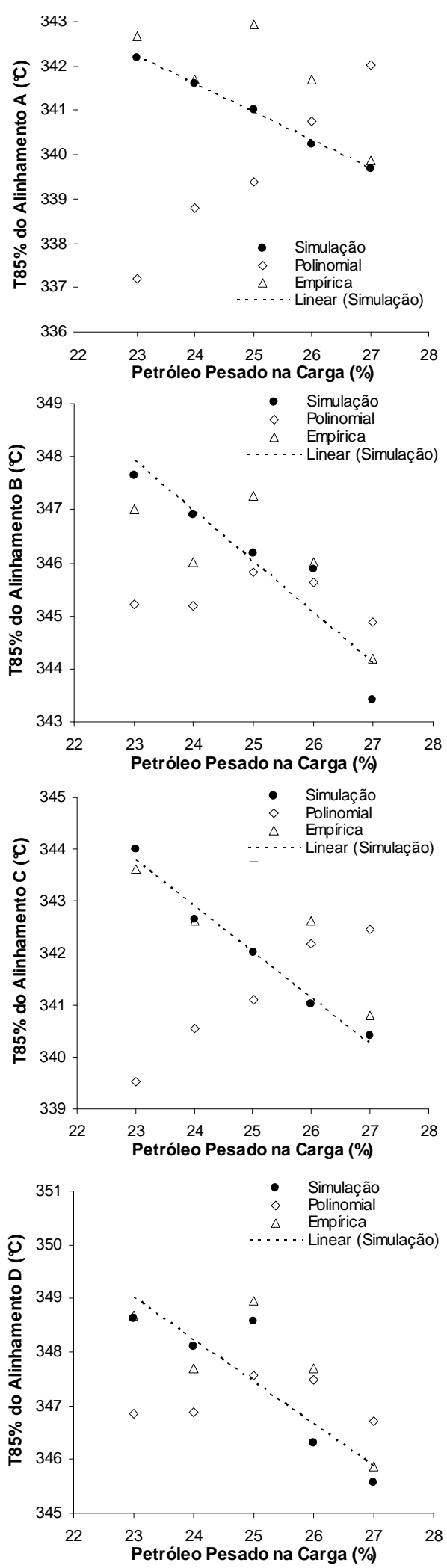

Figura 6.6 - PLO3: T85\% da simulação e dos modelos em relação aos distúrbios. 


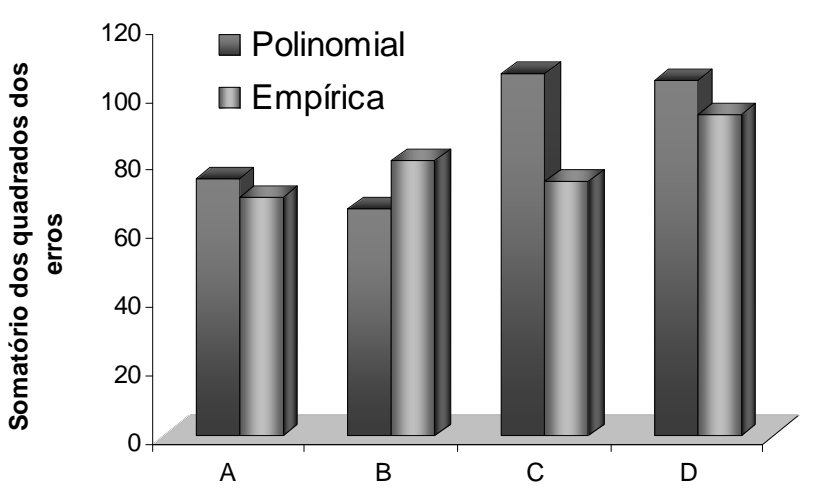

Figura 6.7 - SLO1: Comparação de desempenho dos analisadores virtuais.

causaram o comportamento inesperado dos resultados preditos. Sendo assim a credibilidade dos resultados torna-se duvidosa para este caso em particular.

\subsection{SLO2}

A SLO2 é a segunda linha de operação para o caso 2, ou seja, a análise de sensibilidade para a configuração operacional que visa manter constante o perfil interno de temperatura da torre de destilação quando varia-se a vazão da carga.

A Figura 6.9 ilustra o comportamento da T85\% da simulação e dos modelos em relação à temperatura da alimentação de petróleo na torre, para os alinhamentos A, B, C e D. A Figura 6.10 apresenta o gráfico que relaciona o somatório dos erros quadrados da predição de cada modelo com o seu alinhamento.

A Figura 6.9 mostra os resultados preditos pelos modelos em relação aos distúrbios na carga, onde é possível comparar o desempenho com os dados da simulação. As inferências mostraram-se adequadas para pequenos distúrbios, divergindo dos valores da T85\% padrão à medida que se distanciam do ponto de origem dos Bias. A tendência dos resultados acompanha o comportamento da propriedade originada no Aspen Plus, ao contrário de alguns casos da primeira linha de operação (PLO).

Pela Figura 6.10 é possível perceber que para os alinhamentos A e B a inferência polinomial é mais satisfatória, enquanto que no $\mathrm{C}$ e $\mathrm{D}$ a semi-empírica comporta-se mais adequadamente. $\mathrm{O}$ desempenho dos modelos mostrou-se aleatório sendo que os erros gerados pela rotina semi-empírica simplificada são mais homogêneos quando comparados com os erros daquela de polinômios ajustados
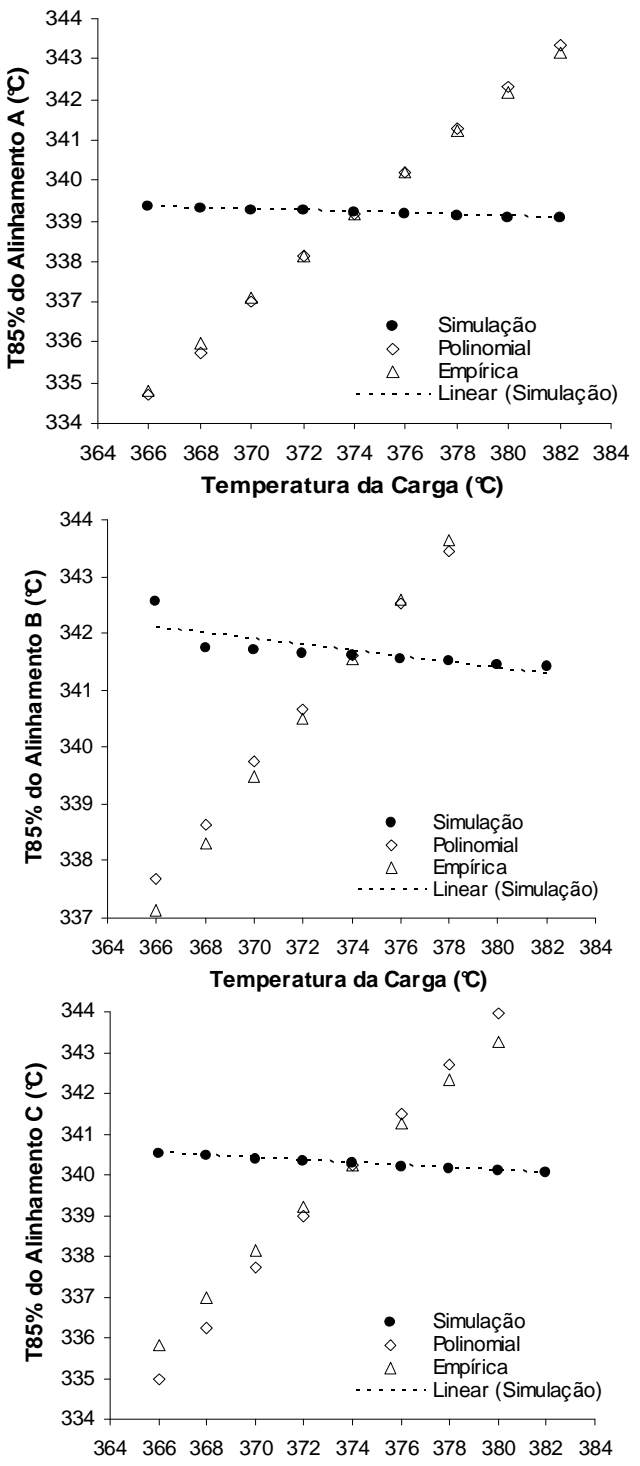

Temperatura da Carga $\left({ }^{\circ} \mathrm{C}\right)$

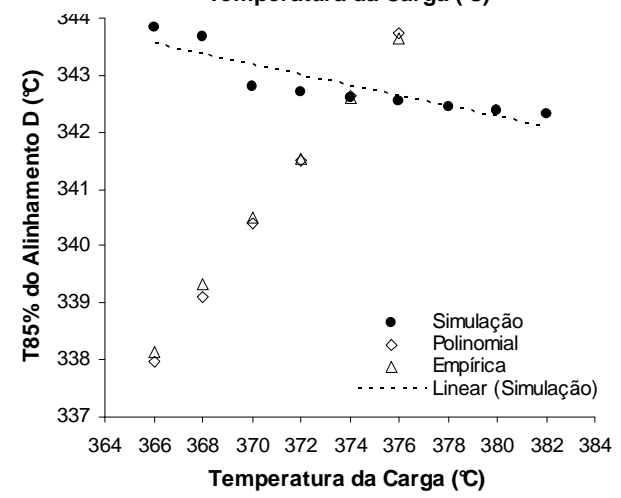

Figura 6.8 - SLO1: T85\% da simulação e dos modelos em relação aos distúrbios.

\section{$6.6 \mathrm{SLO} 3$}

A SLO3 é a segunda linha de operação para o caso 3, ou seja, a análise de sensibilidade para a configuração operacional 

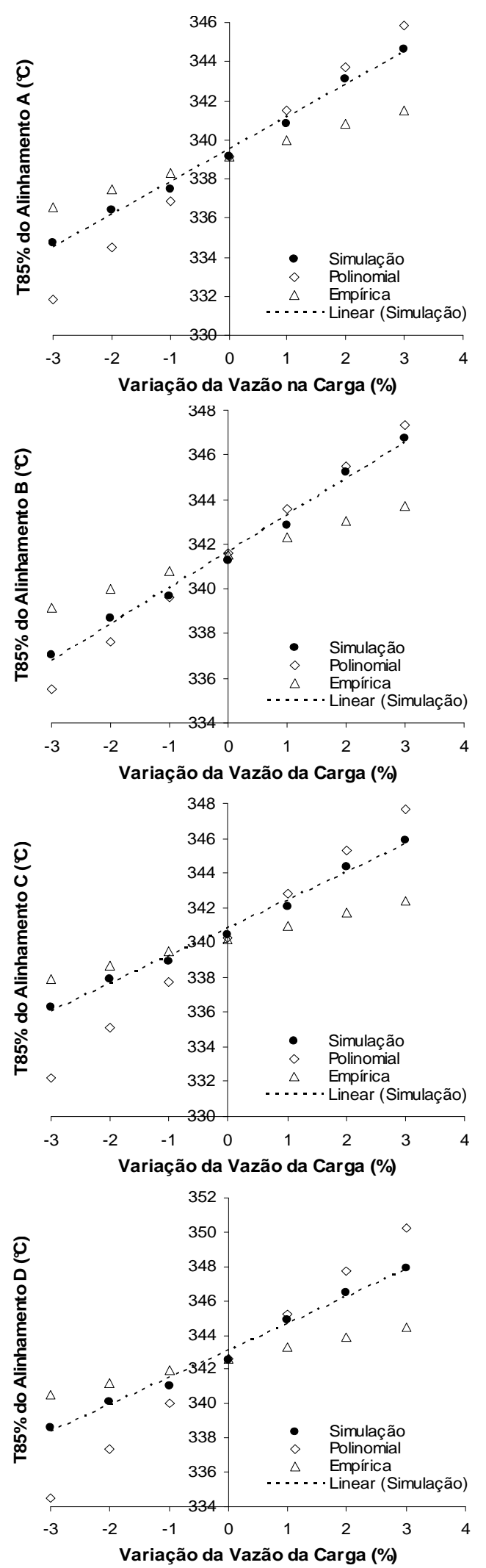

Figura 6.9 - SLO2: T85\% da simulação e dos modelos em relação aos distúrbios.

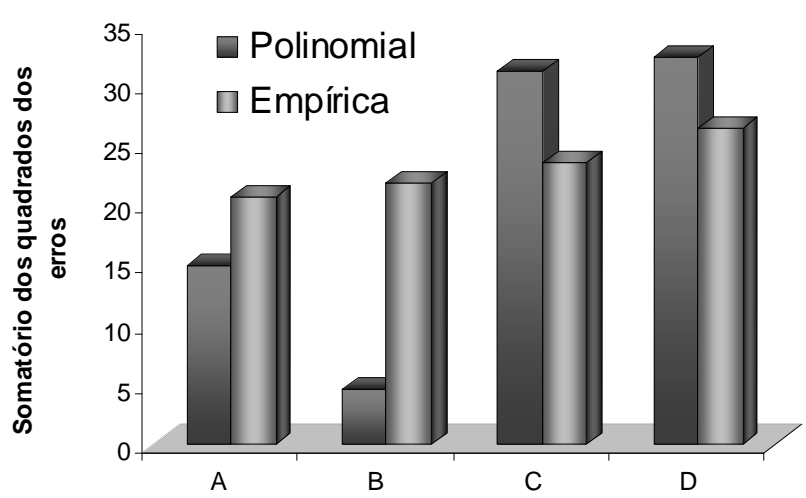

Figura 6.10 - SLO2: Comparação de desempenho dos analisadores virtuais

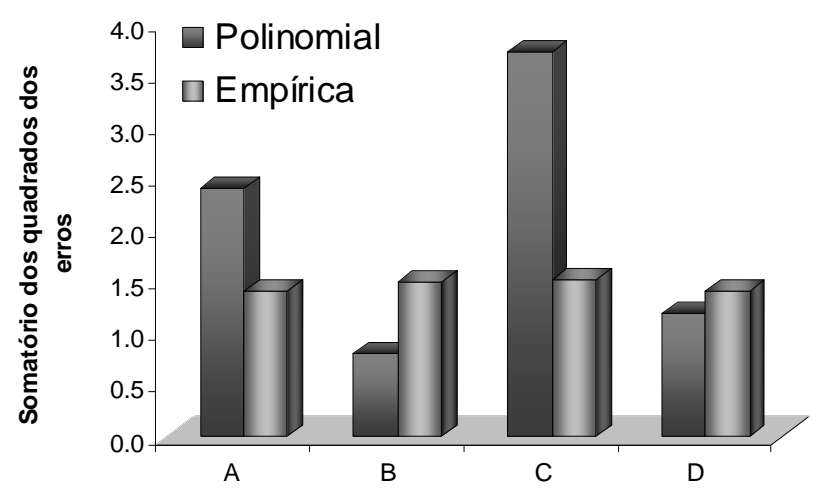

Figura 6.11 - SLO3: Comparação de desempenho dos analisadores virtuais

que visa manter constante o perfil interno de temperatura da torre de destilação quando varia-se a quantidade de petróleo pesado e leve da carga.

A Figura 6.11 apresenta o gráfico que relaciona o somatório dos erros quadrados da predição de cada modelo com o seu alinhamento. A Figura 6.12 ilustra o comportamento da T85\% da simulação e dos modelos em relação à temperatura da alimentação de petróleo na torre, para os alinhamentos A, $\mathrm{B}, \mathrm{C}$ e D.

Os resultados são satisfatórios já que o comportamento considerado padrão (gerado no software Aspen Plus) é representado por ambos analisadores virtuais.

\subsection{Desempenho dos analisadores virtu- ais}

O modo em que o sistema de destilação opera, influi significativamente na predição da T85\%. Os resultados obtidos na PLO não foram tão bons quanto os originados na SLO. Isso ocorreu pelo fato do operador trabalhar com a finalidade de controlar o perfil de temperatura no interior da torre de destilação e os ajustes dos modelos (realizados pelos auto- 

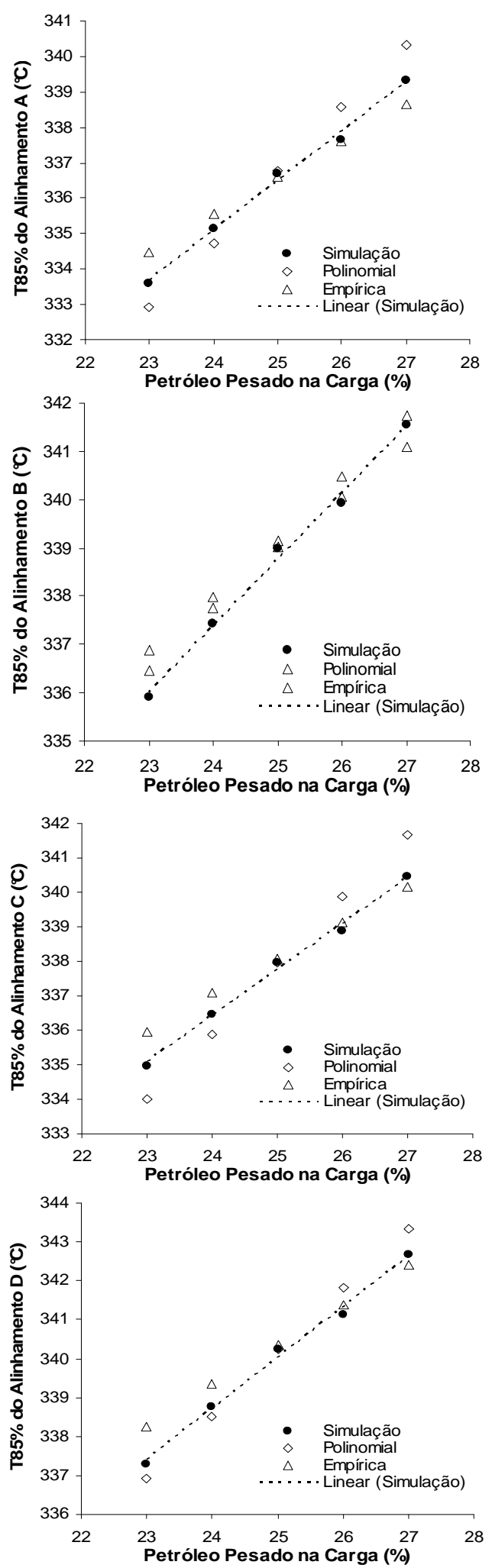

Figura 6.12 - SLO3: T85\% da simulação e dos modelos em relação aos distúrbios. res das inferências) foram feitos com base nesta configuração operacional. Isto significa que uma mudança no perfil de trabalho requer novos ajustes nos parâmetros de ambas as inferências, principalmente na polinomial que se mostrou inadequada para os casos da PLO. Neste contexto a inferência semi-empírica simplificada revelou-se mais robusta.

Segundo Miranda e Lusa (2003), a inferência polinomial requer um maior investimento em engenharia no ajuste das variáveis de maior influência, principalmente se o processo passar por alguma alteração operacional significativa. Esta afirmação pode ser comprovada quando comparados os resultados da PLO e da SLO.

Durante as atividades normais da refinaria, os sistemas responsáveis pelo controle de operação dos processos de destilação visam manter constante o perfil interno de temperatura da coluna. Assim os resultados da SLO são mais apropriados para os testes das inferências. Para essa configuração os resultados mostraram-se coerentes e satisfatórios, visto que as pequenas diferenças de temperatura observadas nos testes entre a predição de um modelo e outro são irrelevantes, já que existem erros de medidas provocados pelos transdutores e ruídos do sistema de instrumentação.

A exceção do modelo polinomial ocorreu com a SLO1, caso em que a fonte de dados foi a análise de sensibilidade da temperatura da carga. Analisando os dados deste caso, percebeu-se que as mudanças significativas ocorrem em apenas duas variáveis: a temperatura da zona de flash e da corrente de RAT. O restante das variáveis demonstrou-se pouco sensível aos distúrbios, e a T85\% resultante da simulação pouco variou. Todavia os resultados gerados pelas inferências comportaram-se de maneira distinta àquela considerada padrão, a gerada pelo Aspen Plus. Quando observada a rotina de cálculos dos modelos percebe-se que o ajuste polinomial leva em conta a temperatura da zona de flash e não a temperatura da corrente de resíduo atmosférico. O inverso ocorre com a inferência semi-empírica simplifica que admite como variável de entrada a temperatura do RAT e não considera variações na zona de flash. Essas variáveis tornam os modelos sensíveis aos distúrbios causando grandes diferenças entre seus valores de saída e os esperados. Possivelmente as temperaturas da zona de flash e da corrente de RAT não sejam variáveis de influência significativa na predição das T85\%.

Exceto a SLO1, os testes representativos de desempenho das inferências foram os da SLO2 e SLO3, que se mostraram adequados para a avaliação dos modelos. A Figura 6.13 ilustra os erros entre os valores preditos e esperados dessas configurações, mostrando que a eficiência dos modelos é semelhante no estado estacionário. Isto significa que os resultados gerados pelos analisadores virtuais são satisfatórios, não havendo grande distinção de resultados. 


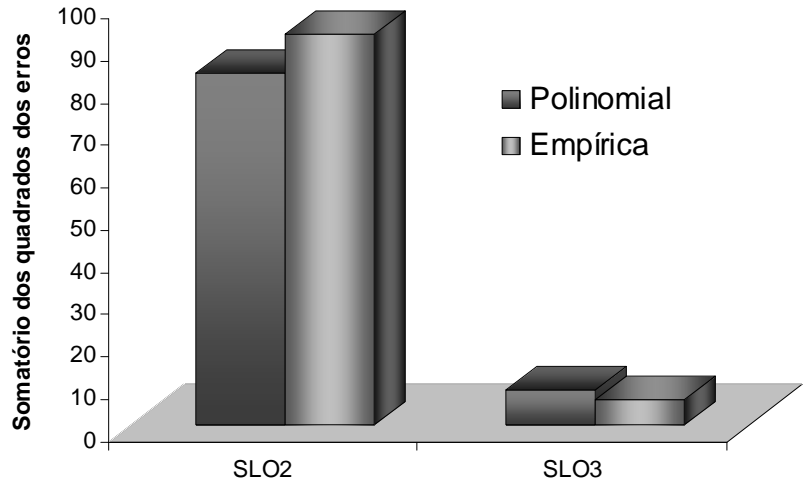

Figura 6.13 - Comparação de desempenho entre as inferências.

Por parte da refinaria, há uma preferência na utilização da inferência de polinômios ajustados. Isto porque o modelo polinomial leva em conta variáveis de dinâmica mais rápida que aquelas usadas no modelo empírico simplificado, tendo um desempenho melhor em estados transientes do processo. As regras de misturas, distintas para cada alinhamento, também são fatores potenciais à melhor acurácia do modelo polinomial. É constante a troca de tanques de alimentação de petróleo e de alinhamentos das correntes efluentes da destilação, fatos que tornam freqüentes a operação em regime transiente, e que obrigam a busca da melhor dinâmica de predição dos analisadores virtuais.

A Figura 6.14 mostra o comportamento dos modelos em período transiente, com interpolação linear ponto a ponto, frente à operação na planta real. A inferência T85\% Nova equivale à polinomial enquanto que T85\% Antiga equivale à semi-empírica simplificada. A linha referente aos resultados de T85\% proveniente de ensaios laboratoriais é mantida constante até entrar uma nova análise. A figura foi cedida pela REFAP S/A. É notável a dinâmica lenta dos resultados do modelo empírico em relação ao polinomial. Deve ser informado que esta comparação também inclui um sistema de correção de bias variável, o que contribui fortemente para os melhores resultados da inferência de polinômios ajustados (Longhi et al., 2007). No que concerne ao estado estacionário inicial da inferência antiga, deve ser explicado que o mesmo é fruto da estratégia de correção de bias (termo independente) da equação. Embora a comparação não seja a mais justa neste sentido, é o fruto de correções que visaram melhorar o desempenho da inferência antiga no tempo anterior ao apresentado na figura. Mesmo desprezando este estado inicial diferente, o comportamento dinâmico da inferência antiga mostrado na Figura 6.14 não representa bem a dinâmica das análises, pois apresenta uma tendência de crescimento contínuo que não está de acordo com o comportamento real desta propriedade. Isso foi observado em vários momentos e não apenas na figura apresentada. A Figura 6.14 foi escolhida, dentre os vários dados existentes,

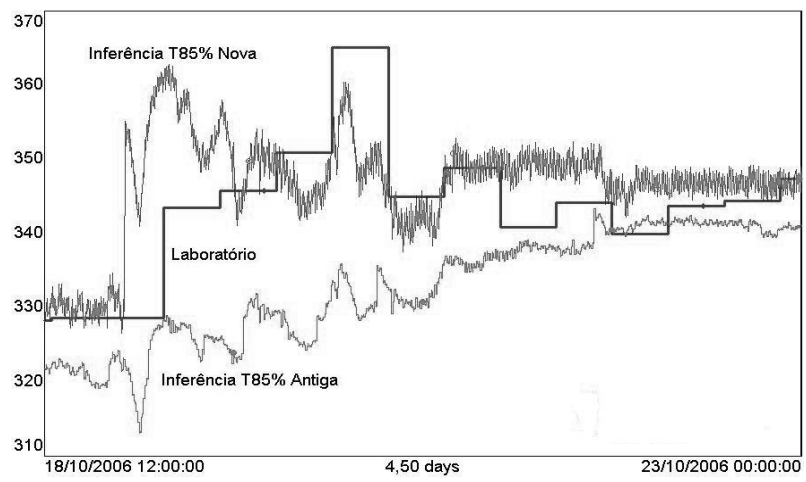

Figura 6.14 - Dinâmica dos resultados das inferências (Longhi et al., 2007).

por mostrar uma situação bastante complexa, pois representa um momento de troca de tanque de carga e de objetivo de produção, para uma mistura de comportamento não-linear de quatro correntes (com trajetos de tubulação e caminhos diferentes) que compõem o produto final, conforme explicado em Longhi et al., 2007.

\section{CONCLUSÃO}

O trabalho desenvolvido pode ser divido em duas etapas principais: a simulação operacional da torre de destilação atmosférica e o teste de modelos preditivos para a propriedade T85\% dos alinhamentos do sistema de refino de óleo cru da Refinaria Alberto Pasqualini - REFAP S/A.

A simulação foi realizada no software Aspen Plus, e a partir das considerações adotadas chegou-se a um modelo que descreve o comportamento do sistema de destilação no estado estacionário. O modelo foi validado com dados operacionais de planta da REFAP S/A. A partir de então foram desenvolvidas análises de sensibilidade, para duas configurações operacionais distintas, que serviram de base para avaliação das inferências.

Duas inferências foram avaliadas utilizando-se como fonte de dados as simulações, onde se concluiu que os dois modelos resultam em estimativas próximas às esperadas. Isto ocorre quando a operabilidade da planta simulada corresponde às condições em que foram desenvolvidos os ajustes para as inferências. Essa condição é aquela que visa controlar o perfil interno de temperatura da torre. O desempenho dos analisadores virtuais foi semelhante para o estado estacionário, todavia a inferência de polinômios ajustados possui melhor desempenho em regime transiente, do que a semiempírica simplificada.

Em alguns testes os resultados foram insatisfatórios por causa da linha de operação, que não corresponde ao trabalho real do sistema. Assim sendo a inferência semi-empírica 
simplificada mostrou-se mais robusta a ponto de se adaptar melhor a mudanças operacionais do equipamento. Isto provavelmente deve-se ao fato desta possuir certa fundamentação teórica e, portanto, algum poder extrapolativo.

Provavelmente algumas variáveis de baixa influência na T85\%, em ambos os casos, prejudicam a eficiência preditiva dos modelos, tornando-os inadequados dependendo da situação a que são submetidos. Isto reduz a confiabilidade dos modelos e obriga os usuários dos mesmos a manutenções periódicas com vistas a atualizar parâmetros de ajustes das rotinas.

Possivelmente atualizações mais freqüentes de Bias resultem em estimativas mais precisas. Um sistema automatizado de atualização de Bias, que reduzisse o tempo gasto na análise laboratorial, poderia incrementar o desempenho dos resultados dos modelos inferenciais e melhorar as especificações comerciais dos produtos.

\section{REFERÊNCIAS}

Aspentech (2001a). Aspen Plus: Getting started building and running a process model. Version 11.1. Aspen Tecnology, Inc. Cambridge.

Aspentech (2001b). Aspen Properties: Physical properties method and models. Version 11.1. Aspen Tecnology, Inc. Cambridge.

ASTM - American Society for Testing and Materials, (2007). "ASTM D86 - 07b Standard Test Method for Distillation of Petroleum Products at Atmospheric Pressure".

Bakhtadze N.N. (2004). Virtual analyzers: Identification approach. Automation and Remote Control, v. 65, n 11, p. 1691-1709. Nov.

Conz V., Trierweiller J.O., Santos O.M. \& Facchin S. (2005). An Industrial Application of Virtual Analyzer for Distillation Columns. 2nd Mercosur Congress on Chemical Engineering, Vila Rio das Pedras - RJ.

Conz V. (2005). Desenvolvimentos de analisadores virtuais aplicados a colunas de destilação industriais. Dissertação de mestrado. Universidade Federal do Rio Grande do Sul, UFRGS, Porto Alegre - RS.

Fortuna L., Graziani S., Rizzo A. \& Xibilia M.G. (2007). Soft Sensors for Monitoring and Control of Industrial Process. Springer, London.

Gonzalez G. D. (1999). Soft Sensors for processing plants. In: Proc. 2nd International Conference on Intelligent Processing and Manufacturing of Materials, IPMM 99, v. 1, p. 59-70, Hawaii.
Kalid R.A. Controle de Coluna de Destilação. Disponível em <http://www.lacoi.ufba. br/imagens $\left\{\backslash_{-}\right\}$Lacoi/docs $\left\{\backslash_{-}\right\}$pdf/

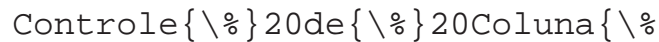
\} 20 de $\left\{\backslash \frac{0}{0}\right\} 20$ Destilacao.pdf $>$. Acesso em: 20 ago. 2006.

Longhi L.G.S., M.M Rodriques \& F.S. Duarte (2007). Desenvolvimento de inferências para controle avançado em unidade de destilação atmosférica. Rio Automação, Rio de Janeiro.

Matar S. \& Hatch L.F., (2000). Chemistry of Petrochemical Process. 2 ed, GPP Gulf Professional Publishing, Houston.

Miranda F.C. \& Lusa L.P., (2003). Inferências para controle de uma torre de destilação atmosférica de uma refinaria. ISA Show Brasil 2003, $3^{\circ}$ Congresso Internacional de Automação, Sistemas e Instrumentação, ISA Distrito 4, São Paulo.

Ondrey G. (2005). Simulation and modeling spread their wings. Chemical Engineering, n. 5, p. 27-31.

Parkash S., (2003). Refining processes handbook. Elsevier, New York.

Perry's R.G., C.H Chilton \& S.D. Kirkpatrick (1999). Chemical engineers handbook. McGraw-Hill, New York.

Riazi M.R., (2005). Characterization and Properties of Petroleum Fractions. American Society for Testing and Materials, Philadelphia.

Secchi A.R., Cardozo N.S.M., Almeida Neto E. \& Finkler T.F., (2006). An Algorithm for Automatic Selection and Estimation of Model Parameters. Proceedings of the International Symposium on Advanced Control of Chemical Processes (ADCHEM 2006), vol. 2, p. 789-794. Gramado, Brasil.

Watkins R.N. (1981). Petroleum refinery distillation. 2.ed, GPP Gulf Professional Publishing, Houston. 